\title{
The Relationship of Gifted Program Enrollment to Race/Ethnicity, Gender, and SES
}

\author{
Allison List ${ }^{1}$ and Cass Dykeman ${ }^{2}$ \\ 1,2Oregon State University \\ ${ }^{1}$ Corresponding Author: lista@oregonstate.edu
}

This is the author's preprint. This preprint has been submitted to a peerreview journal.

\begin{abstract}
Disproportionalities in gifted and talented enrollment exist among individuals regardless of race/ethnicity, gender, or socioeconomic status (SES). Inequities are most pronounced for/in cases where race/ethnicity and SES are factors. To discern why specific student groups benefit from gifted program access, while others do not, a crosssectional observational design was applied to extant data from a large school district that included both rural and urban schools. Proportional distribution among race/ethnicity, gender, and SES was evaluated using prevalence rates and a onesample $z$ test of proportions. Results showed that, while disproportionalities existed across all variables, student racial groups exhibited the most disproportional distribution. These findings indicate that issues driving disproportionality in gifted education go deeper than acknowledged by previous arguments. Historic and current conceptualizations of giftedness rest on a culture-bound construct that perpetuates disproportionate representation of student groups. Gifted measures and assessments of intellect are biased, excluding some while benefiting others, and thus gifted identification procedures and assessments warrant heightened scrutiny. Keywords: disproportionality, underrepresentation, identification, race, SES, gender, gifted.
\end{abstract}

\section{Introduction}

Modern public education is rife with examples of inequity, including disparities in gifted and talented programs. As an attribute or ability, giftedness transcends demographic groups; but still, there are specific types and classes of students who are routinely underrepresented in gifted and talented programs. Enrollment data for these programs reflect differences in proportional distribution among students (Civil Rights Data Collection [CRDC], 2014). Students of color, as well as students living in poverty, have faced limited access to gifted education opportunities (Callahan, 2005; Ford, Grantham, \& Whiting, 2008; Hamilton et al., 2018; Wright, Ford, \& Young, 2017). Both students of color and those living in poverty have been underrepresented since the birth of gifted education programming (Callahan; Ford et al.), with the consequences reinforcing stereotypes of intellectual inferiority.

Within the little published research that focuses on gifted education inequities, there are two general themes. First, researchers have pointed to inadequate gifted 
identification processes and measures of intelligence as factors driving disproportionality (Card \& Giuliano, 2016; Lohman \& Gambrell, 2016; Naglieri \& Ford, 2003; Yaluma \& Tyner, 2018). While, other researchers have emphasized the consequences of inequities in processes for identifying gifted students, presenting these practices as, on the whole, a troublesome reinforcement of Western perceptions of the intellectual capacities of diverse student groups (Ford, 2010; Ford et al., 2008; Goings \& Ford, 2018).

Attention from only a small group of concerned scholars is insufficient to influence change; as a society, we should all be challenging, not accepting, the fact that the gift of opportunity to exercise and strengthen intellect has been reserved for only selected students. Advocacy informed by scholarship should focus on revealing the deeply rooted disparities among student groups, causes that go beyond the contributing factors with which we are already familiar. It is time to challenge the status quo by holding gifted identification practices accountable for the disproportionalities they have established, reinforced, and even normalized in American education.

In order to address disproportionalities in gifted education, Critical Race Theory (CRT) will be utilized. Writing through the lens of CRT communicates a different viewpoint that is often drowned out by the mainstream narrative (Bell, 1995). CRT positions the problem of gifted inequities within an educational, political, and historical context (Daftary, 2019). The story of underrepresentation in gifted programs is one with historical roots in systemic inequity in education and contributes to the marginalization of students of color and those living in poverty. The perspective of those who are underrepresented is a voice that is not equally heard or equally valued as supported by studies that produce data that consistently reflects historical gifted disproportionality (Callahan, 2005; Ford et al., 2008; Hamilton et al., 2018; Wright, Ford, \& Young, 2017). The application of CRT attempts to bring about awareness of the prevalence of racial and class dominance in gifted education frameworks.

The present study's examination of the literature on the relationship between gifted program enrollment and race/ethnicity, gender, and SES attended to the following seven primary themes: (a) the definition of giftedness, (b) the purpose of gifted programing, (c) the prevalence of gifted programing, (d) gifted identification, (e) gender differences occurring in gifted enrollment patterns, (f) race/ethnicity differences evident in gifted enrollment patterns, and (g) SES differences present in gifted enrollment patterns. A discussion of the research questions guiding this study will follow the explication of the above themes.

Much debate has surrounded the mere definition of giftedness. Renzulli (1978) theorized that the needs and values of one's culture determine whether one is recognized as gifted. While there is no universally accepted definition for this notion, according to the National Association for Gifted Children (NAGC), federal law stipulates that the term gifted and talented refers to:

students, children, or youth who give evidence of high achievement capability in such areas as intellectual, creative, artistic, or leadership capacity, or in specific academic fields, and who need services or activities not ordinarily provided by the school in order to fully develop those capabilities. (NAGC, 2017) 
States use this federal definition as a guide for informing their operationalizations of giftedness as well as associated policies and practices for reaching and teaching gifted students.

Still, while the federal version affords some direction, constructions of giftedness vary greatly among states (Stephens \& Karnes, 2000), with some states having yet to adopt any official definition (NAGC, 2017). The 2014-2015 State of the States in Gifted Education report showed that, currently out of U.S. states, 37 had definitions of giftedness, and that, language addressing diverse student populations was rarely included in the descriptions set forth by those 37 states (NAGC, 2015). For example, only nine states referred to the needs of low SES students; only eight states addressed the needs of English Language Learners (ELLs), as well as those students deemed culturally or ethnically diverse (CLD); only six states contemplated students designated twice-exceptional (i.e., gifted and disabled); and a mere three states recognized issues of geographical isolation (NAGC).

Even amid variance in both the prevalence and the conceptualization of gifted definitions, the literature demonstrates a shared purpose in supporting specific programs that foster, strengthen, and develop gifted students (Archambault et al., 1993; Callahan \& Hertberg-Davis, 2012; Campbell \& Walberg, 2010; Farkas \& Duffet, 2008; Reis \& Renzulli, 2010). Reis and Renzulli pointed to gifted programs as offering a better fit for students identified as gifted, as opposed to what those students might experience in a general education setting.

In a national survey given to classroom teachers, Archambault et al. (1993) found that $61 \%$ of general education teachers reported having never received training on gifted students or gifted teaching pedagogy. Farkas and Duffet (2008) confirmed such findings, noting that $65 \%$ of preservice teachers self-reported experiencing little to no training in their teaching programs in terms of how best to support academically advanced students. As a function of this relative inattention to the special nature of gifted education, Callahan and Hertberg-Davis (2012) observed that the bulk of teachers' knowledge regarding differentiation is derived from supporting students who are below grade level. Gifted students not enrolled in gifted programs could, therefore, be at risk of stagnant academic performance.

Gifted programs have proven to be beneficial for high-achieving students, a finding demonstrated by many researchers (Archambault et al., 1993; Callahan \& Hertberg-Davis, 2012; Campbell \& Walberg, 2010; Farkas \& Duffet, 2008; Reis \& Renzulli, 2010); but it is also essential to accurately assess the accessibility of these options. Until recently, exact data on the prevalence of gifted programs was hard to come by; as one example, Yaluma and Tyner (2018) reported that $68.3 \%$ of public elementary and middle schools currently offer gifted programs to qualified students.

There are, however, several issues that have, heretofore, complicated efforts to gather such information. First, there are no federal mandates that apply to gifted education, as program decisions are handled locally, within each state (NAGC, 2017). The governing structures in place within individual states, ranging in strength, contribute to inconsistent or unavailable reporting and accountability measures across the country (Brown, VanTassel-Baska, Worley, \& Stambough, 2006). Second, the 2014-2015 State of the States in Gifted Education report accounted for the absence of data on program prevalence by emphasizing that (a) three states do not have staff dedicated to gifted 
education, (b) 24 states have gifted staff who administer other programs concurrently, (c) 19 states do not audit or monitor their gifted programs, and (d) 28 states do not use accountability forms (NAGC, 2015).

In a broader sense, a third contributing factor flows from the No Child Left Behind Act (NCLB, 2002). During the time of NCLB, fewer gifted programs existed because government funds went to students who were working below grade level (Beisser, 2008). Finally, factors contributing to the data gap stem from policies of the U.S. Department of Education. However, in 2011, the Office for Civil Rights (OCR) made strides to close the data gap by asking states to report disaggregated data based on race and ethnicity categories, giving more specific information for gifted program student enrollment (Office for Civil Rights, 2018). While a step in the right direction, states were still not mandated to respond.

While the OCR created opportunity in the realm of gifted program analysis, the implementation of the Every Student Succeeds Act (ESSA), which, in 2015, replaced NCLB, was a crucial turning point for the state of gifted education because the new law required states to, on an annual basis, report disaggregated data on student achievement addressing various demographic markers such as: (a) race/ethnicity, (b) low-income status, (c) ELL designation, (d) gender, and (e) disability designation (ESSA, 2015). The downside of this change-of the requirement for more collection, administration, and reporting of data-reflects the level of gifted program policy within a state. If data on gifted student identification goes unrecorded at the state level, then interpretation should be approached with caution because in terms of achievement students considered "high-achieving" are not necessarily those who have been deemed gifted

In the wake of the ESSA and due to the OCR's efforts, Yaluma and Tyner (2018) reported gifted program prevalence rates, extracting data from the 2014-2015 CRDC series, as well as the 2015-2016 data from the National Center for Education Statistics (NCES), which included data from the ESSA. While Yaluma and Tyner took steps in terms of reporting on program prevalence, their study was limited because types of gifted programs and services were unknown within these data

The limitation of the Yaluma and Tyner study (2018) relates to the absence of federal mandates regarding gifted education and accountability, an absence that ultimately gives states the authority to provide gifted education as deemed necessary, if at all (NAGC, 2017). Currently, 28 states mandate their internal districts to provide services for gifted learners, while 32 states provide programs and services for specific areas of giftedness, as discussed in the 2014-2015 State of the States in Gifted Education report (NAGC, 2015). This leaves the state of gifted education a mystery for at least one third of the nation.

Scholars working in the field, gifted stakeholders, and the U.S. Department of Education are best suited to holding states more accountable for their gifted programs. Having quantitative data allows interested parties to highlight recurring social justice issues, such as disproportionalities in enrollment. These types of disproportionalities appear to initiate with gifted program opportunities, options, and availability-pointing to access as the great inequity in gifted education.

Traditional gifted identification methods have been under scrutiny for years, decried for contributing to gifted program disproportionality and underrepresentation 
(Card \& Giuliano, 2016; Callahan \& Hertberg-Davis, 2012; Morris, 2001; Naglieri \& Ford, 2003). As an example, Marquardt and Karnes (1995) investigated discriminatory cases filed with the OCR from 1985 to 1991 and discovered that $77 \%$ of cases concerned discrimination claims involving Black students and their access to gifted education. While traditional gifted identification methods, such as IQ tests, have historically served as valid measures of intelligence, other research has shown that mean IQ scores differ across groups, raising concerns that these measures could be racially biased in effect even if not in intent (Callahan, 2005; Callahan \& Hertberg-Davis; Naglieri \& Ford).

These findings have informed the use of other approaches to gifted identification that were designed to close the opportunity gap for underrepresented populations. One approach, discussed by Yaluma and Tyner (2018), specifically addressed the use of universal screening methods as policy implications. Another approach is a specific universal screener, notably the Naglieri Nonverbal Ability Test (NNAT). Naglieri and Ford's (2003) administration of the NNAT found that the mean differences in high standard scores between White students and students of color were small, meaning percentages of students identified as gifted were similar across racial groups. Card and Giuliano (2016) used the NNAT in their study and found that it increased gifted program participation for students of color and students living in poverty by $180 \%$. Yet, while this assessment method has shown promise, most states continue to use traditional techniques, including IQ testing and nomination methods (McBee, 2006).

Nomination methods are a persistent problem for both students of color and students living in poverty (Callahan, 2005; Ford et al., 2008; McBee, 2006; Naglieri \& Ford, 2003; Swanson, 2006). Such methods are often the initial step in gifted identification, and extending the responsibility for nominations to educators can be problematic, leaving room for bias. For example, the typical Western and middle-class values of educators could, whether knowingly or not, anchor the nominators' conceptualizations of and assumptions about gifted behavior (Sternberg, 2018; Yoon \& Gentry, 2009).

Consider the results from a study examining identification for gifted programs in Georgia, where teacher nomination methods were part of a multi-step identification process. As McBee (2006) revealed with respect to the Georgia process, $12.3 \%$ of White students qualified for gifted programming, compared to only $3.2 \%$ of Black students and $2.3 \%$ of Hispanic students. Of these racial-group findings, identification rates were higher across the board in upper-class groups. For example, of the $12.3 \%$ of White students who qualified for services, $4.4 \%$ were of low SES, while $15.6 \%$ registered as high SES. Of the $3.2 \%$ of Black students who qualified, $2.2 \%$ were of low SES, while 5.4\% registered as high SES (McBee). These data reflect larger trends associated with socioeconomic status and race, thereby impacting students' opportunities and perpetuating disproportionalities.

But differences in proportional distribution are also evident between males and females. Petersen (2013) discovered that, when course grades served as a primary form of gifted identification, girls were identified more often than boys were during their elementary years. The 2014-2015 State of the States in Gifted Education report showed the demographic breakdown of gifted program enrollees and found that, of the 21 states that responded, 11 had higher percentages of females identified, seven 
identified more males, and three showed an even split between males and females (NAGC, 2015). In a study conducted by Pfeiffer and Jarosewich (2007), using a multistep identification process, data revealed small but significant differences in gender identification for giftedness, with higher identification rates in females. However, Petersen's meta-analysis of 120 studies showed that, when using IQ and standardized scores to identify giftedness, boys were more likely to be identified than girls. It appears that the identification measures employed are related to differences between genders.

While it is possible that females are overrepresented in their early years of schooling, an important developmental shift happens in the adolescent years. Sadker (2000) noted that, although girls may be identified at higher rates in their younger school years, by 10th grade they drop out of gifted programs with greater frequency than boys. Pepperell and Rubel (2009) revealed that a social-emotional shift happens for girls in middle school. Female participants struggled to regulate their giftedness, both in terms of aspiring to succeed and trying to fit in within the social environment (Pepperell \& Rubel). Broadly speaking, gender differences appear in elementary school, while inverting once adolescent males and females reach secondary school.

Available data indicate disproportionalities of a different kind for racial groups. Racial minorities are underrepresented in gifted programs, and traditional identification methods have long been criticized for contributing to gifted program disproportionality and underrepresentation (Callahan \& Hertberg-Davis, 2012; Morris, 2001; Naglieri \& Ford, 2003). According to Ford (1998), gifted education programming has historically evinced ethno-racial biases, while showing minimal interest in remedial efforts. For example, when examining teacher nomination methods used to identify potentially gifted students, data have shown that Black and Hispanic students are less likely to be nominated than their White counterparts (McBee, 2006). In the same vein, Grissom and Redding (2015) referenced a 2009 report from the CRDC which revealed that Black students made up only $9.8 \%$ of the total gifted student population, despite representing $16 \%$ of the U.S. population, while the gifted Hispanic student population was $15 \%$ and the Hispanic share of the U.S. population was $22 \%$.

Current research indicates the same trends in terms of racial underrepresentation. Yaluma and Tyner (2018) reviewed participation in gifted programs in high-poverty schools and found that Black and Hispanic students enrolled in gifted programs at lower rates than their Asian and White peers. Specifically, Yaluma and Tyner found that Black students amounted to $25.4 \%$ of the total student population but only $19.3 \%$ of the gifted program, while Hispanic students totaled $50.3 \%$ of the total student population but only $43.7 \%$ of the gifted program. In the same sample, White students made up $17.5 \%$ of the student population but represented $25.7 \%$ of the gifted program; meanwhile, Asian students were 2.7\% of the total student population but $5.8 \%$ of the gifted program (Yaluma \& Tyner). Finally, when shifting their focus to include the added variable of poverty within the academic setting, Yaluma and Tyner found that Black students comprised $4.8 \%$ of the total student population in low-poverty schools but only $2.6 \%$ of the students in gifted programs, while Hispanic students represented $11 \%$ of the total student population in these same schools but only $7 \%$ of the students in gifted programs. Asian students were still overrepresented in the case of low poverty schools, with $16 \%$ being identified as gifted despite a $10 \%$ representation in the general 
student population (Yaluma \& Tyner). Meanwhile, the representation of White students (69\%) was, in this case, proportional (Yaluma \& Tyner).

The number of studies addressing inequities in ethnic and racial minority distribution in gifted education is small, but research is growing. Of studies on gifted education conducted from 1966 to 1996, only 8\% contemplated underrepresented populations (Ford, 1998). Even more, published articles dealing with racial and ethnic underrepresentation in gifted programming have limited their attention to issues of gifted identification, deficit thinking, recruitment methods, and retention methods (Ford, 2010; Ford et al., 2008; Grissom \& Redding, 2015, Morris, 2001; Naglieri \& Ford, 2013).

Like other groups discussed above, students from low-income households are under-identified for gifted services (Peters \& Gentry, 2010). Indeed, disproportionate rates in gifted education have always been present and steady for students living in poverty and for students of color (Callahan, 2005; Ford et al., 2008). Socioeconomic status has influenced student identification rates in gifted programs (McBee, 2006), even when achievement and race are controlled for (Hamilton et al., 2018; Slocumb \& Payne, 2000). Such findings reinforce Ford's (2010) call for researchers to resist using poverty as a proxy for race.

Results from Hamilton et al. (2018) suggest a relationship between high poverty schools and gifted identification rates. Schools that held higher Free and Reduced Lunch (FRL) rates had lower gifted student identification rates (Hamilton et al.) which aligned with findings from Yaluma and Tyner's (2018) study. Additionally, the authors found that both institutional poverty (i.e., income inequality) and individual poverty helped explain pieces of the disproportionality puzzle making up gifted programs (Hamilton et al.). On this note, McBee (2006) evaluated SES levels among gifted racial groups and found that, of the $12 \%$ of White students who qualified for services, $4 \%$ were of low SES, while 15.6\% registered as high SES. Meanwhile, of the 3\% of Black students who qualified, $2 \%$ were of low SES and $5 \%$ registered as high SES (McBee, 2006).

As these data make clear, socioeconomic status impacts student opportunity. While there is certainly an association between the racial and socioeconomic variables discussed above, future research must recognize the distinctive contributions of each influence, resisting the over-relation of factors. Socioeconomic status presents its own challenges for scholars and practitioners; the scant number of low SES students in gifted programs reinforces the socially constructed assumptions of educators that one must be from either a middle- or upper-class background to achieve (Grantham, 2002; Yoon \& Gentry, 2009) or that students of color must always be associated with low SES situations (Ford, 2010).

Such biases perpetuate the cycle whereby low SES students with great potential go unnoticed by the system (Peters \& Gentry, 2010). In a review of studies, Goings and Ford (2018) showed that most scholars looked at how poverty impacts students, rather than focusing on the systemic barriers that create and reinforce inequality in the first place. For their part, Olszewski-Kubilius and Corwith (2018) recommended that future studies explore poverty's systemic impact on giftedness. Gifted programs have begun implementing universal screeners for student identification with the hope of addressing such inequities. 
Still, methods of identification that do not account for environmental opportunities will always, to some degree, exclude gifted students living in poverty. This is because standardized assessment identifies opportunity rather than giftedness (Slocumb \& Payne, 2000). Students living in poverty lack both quantity and quality of access to opportunity, thereby affecting academic performance and disadvantaging those from low SES households when measured against skill sets rooted in middle-class opportunity norms (Slocumb \& Payne). Standard gifted identification methods often miss gifted youth living in poverty, contributing to identification disproportionality.

Many factors contribute to underrepresentation in gifted education, as is evident from the above discussion, but the present study was designed to help us better understand one portion of the larger problem: specifically, the nature and implications of disproportionalities in gifted and talented education. Two research questions guided this exploration. The first question was: Considering elementary students enrolled for gifted services, what were the prevalence rates according to race/ethnicity, gender, and SES? And the second question was: Are the proportions of elementary students enrolled for gifted services, when organized according to race/ethnicity, gender, and SES, commensurate with the proportions of elementary students according to those same categories within the general population?

\section{Design}

\section{Method}

The present study employed a cross-sectional observational design using archival (i.e., pre-existing) data (Mann, 2003). The variables included (a) race/ethnicity (binomial), (b) gender (binomial), and (c) SES (binomial). An a priori power analysis, using G*Power 3.1 (Faul, Erdfelder, Buchner, \& Lang, 2009), helped determine the necessary sample size for the second research question. Given the one sample and the binomial nature of the research variables, the power analysis was for a difference from a constant. The proper effect size is Cohen's $h$ (Rosnow \& Rosenthal, 2003). The effect size came from Harris, Rowley, Beck, Robinson, and McColgan (2011). The constant proportion of males was pulled from the same state where the study was conducted (Kids Count Data Center, 2016). The G*Power inputs were as follows: (a) test family: exact, (b) statistical test: proportion: difference from constant (binomial test, one-sample case), (c) type of power analysis: a priori: compute required sample size, (d) tails: two, (e) effect size $g=.14$, (f) $\alpha$ error probability $=.05$, (g) power $(1-\beta$ error probability $)=.80$, and $(h)$ constant proportion $=.51$. The $G^{*}$ Power 3.1 output included a sample size of 101 and an actual power of 0.81 and $(e) \alpha=.05$.

\section{Participants}

Data drawn from the 2015-2016 academic year and involving 4,000 first-grade students were collected from a large school district, containing urban and rural schools, located in the western United States. Every first-grade student received the Cognitive Abilities Test Form 7 (CogAT) as a universal screening device to guide academic talent identification. The data on these 4,000 students included the following for every child: (a) cognitive aptitude score, (b) age, (c) gifted identification marker, (d) gifted program service approval, (e) FRL status (serving as a proxy for SES), (f) gender, and (g) race. The cognitive aptitude score had a mean of 100, with a standard deviation of 16 . With reference to age, the participants were almost equally split between 9-year-olds (49\%) and 10 -year-olds (51\%). Participant SES consisted of $56 \%$ coded as high and $44 \%$ 
coded as low based on FRL status. In terms of gender, $55 \%$ were female, while $45 \%$ were male. Lastly, the racial makeup of participants consisted of American Indian/Alaskan Native (1.3\%), Asian (3.4\%), Black (1.8\%), White (44.7\%), Hispanic (42.1\%), multi-racial (5.4\%), and Pacific Islander (1.3\%). Regarding analysis, race/ethnicity, gender, and SES were the only variables retained from the data set. Measures

Gifted Program Enrollment Status. Program enrollment was coded as $0=$ No and $1=$ Yes.

Population Race Proportions $\left(\boldsymbol{p}_{0}\right)$. Race was divided into two groups: $0=$ historically underrepresented (American Indian/Alaskan Native, Black, Hispanic, Pacific Islander, and multi-racial) and 1= historically overrepresented (Asian and White). The proportion was drawn from the total student population by under- and overrepresented racial groups.

Sample Race Proportions $(\hat{\boldsymbol{p}})$. Race was divided into two groups: $0=$ historically underrepresented (American Indian/Alaskan Native, Black, Hispanic, Pacific Islander, and multi-racial) and 1= historically overrepresented (Asian and White). The sample proportion was drawn from students who enrolled in gifted programs by underand overrepresented racial groups.

American Indian/Alaskan Native. American Indian/Alaskan Native was converted to the term Indigenous and was coded as I during analysis.

Population Gender Proportions $\left(p_{0}\right)$. Dummy coding was used for gender, where $0=$ male and $1=$ female. The population proportion was drawn from the total student population by gender.

Sample Gender Proportion ( $\hat{\boldsymbol{p}})$. Dummy coding was used for gender, where $0=$ male and $1=$ female. The sample proportion was drawn from students who were enrolled in the gifted program.

Population SES Proportions $\left(\boldsymbol{p}_{0}\right)$. FRL status served as the proxy for SES (Harwell \& LeBeau, 2010). The dummy coding for this variable was $0=$ not low SES (i.e., not FRL-qualified) and $1=$ low SES (i.e., FRL-qualified). The population proportion was drawn from the total student population by SES.

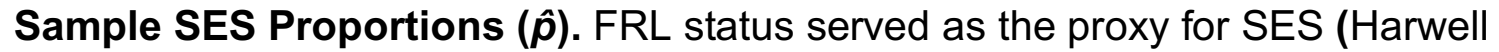
$\&$ LeBeau, 2010). The dummy coding for this variable was $0=$ not low SES (i.e., not FRL-qualified) and $1=$ low SES (i.e., FRL-qualified). The sample proportion was drawn from students who were enrolled in the gifted program.

\section{Data Analysis}

The first research question concerned prevalence and employed measures of central tendency and percentages. The second research question examined proportional differences on different demographic variables between gifted students and the entire student population. All three demographic variables were binomial. When analyzing an observed binomial variable (i.e., $\hat{p}$ ) against a known population proportion (i.e., $p_{0}$ ), a one-sample $z$ test of proportions is appropriate (Daly \& Bourke, 2008). The significance level for all analyses was set at .05. All analyses were conducted using the statistical programming language, $R$.

\section{Results}

The analysis of the first research question, regarding prevalence, generated raw counts and percentages in gifted program enrollment across race/ethnicity, gender, and 
SES. Taken together, the percentage of Asian and White students (typically overrepresented) who enrolled in a gifted program was $77.71 \%$ (a raw count of 136 out of 175 students). Meanwhile, the percentage of Black, Hispanic, Indigenous, multiracial, and Pacific Islander students (typically underrepresented) who enrolled in a gifted program was, when combined, only $22.29 \%$ (a raw count of 39 out of 175 students). Regarding gender, the percentage of females who enrolled in a gifted program was $42.86 \%$ (a raw count of 75 out of 175 students). In terms of the SES variable, where FRL status was used as a proxy, the percentage of students who enrolled in a gifted program, and who were FRL qualified (i.e., low SES) was $24 \%$ (a raw count of 42 out of 175 students).

In terms of the second research question, which measured proportional differences across binomial variables, the one-sample $z$ test of proportions produced statistically significant results with respect to race/ethnicity, gender, and SES levels. Effect sizes are reported using Cohen's $h$. In terms of race/ethnicity, results for the historically overrepresented racial groups (i.e., Asian and White) were as follows: $p_{0}=$ $.48, \hat{p}=.77$, and $p=<.05$. Results for the historically underrepresented racial groups (i.e., Black, Hispanic, Indigenous, multi-racial, and Pacific Islander) were as follows: $p_{0}$ $=.52, \hat{p}=.23, p=<.05$, with $h=.624$. With respect to gender, results for females were as follows: $p_{0}=.50, \hat{p}=.42, p_{0}=<.05$, with $h=.154$. Finally, in terms of SES, results for students who were FRL qualified were as follows: $p_{0}=.57, \hat{p}=.24, p=<.05$, with $h=$ .674

\section{Discussion}

The observed percentages associated with the first research question (concerning prevalence in gifted program enrollment across demographic variables) describe the rate of gifted enrollment, for different demographic groups, existing in the sample. Such results could be a function of the single homogenous sample obtained, while an alternative explanation could be that the CogAT does not, itself, identify giftedness equally across groups (Lohman, 2012). Both explanations are plausible, but the most logical is the latter option, because the CogAT is known to reduce (but not diminish) group differences; therefore, discrepancy across groups in enrollment is to be expected when using the CogAT.

Results for the second research question (inquiring of differences in proportions across variables of race, gender, and SES) reflected that statistically significant disproportionalities exist in the sample across all variables. While the findings are consistent with previous research in the above literature review, further analysis is warranted to arrive to potential reasons for the obtained results.

Potential reasons for the obtained results concerning race/ethnicity and SES include: (1) a construct of giftedness based upon $\mathrm{G} f$ is inadequate, (2) $\mathrm{G} f$ is an adequate construct but the primary measure of the construct (i.e., CogAT) is inadequate, (3) the utility of the CogAT was used inappropriately, and (4) the differences in achievement across groups exist because of some unidentified third variable(s).

An argument for the first potential reason (i.e., G $f$ construct) can be made as to why the disproportional enrollment results were obtained. Cattell (1963) conceptualized Gf as the following: (1) the capacity to perceive relations and educe correlates, (2) is mostly biologically and physiologically determined, (3) is affected by gestation period 
influence and later physical trauma and physiological change, and (4) operates independent of cultural knowledge or experience. However, research subsequent to Cattell's work has documented the strong interactional nature between variables such race, SES, and experiences such as trauma (e.g., Berger, 2019). As such, there exists sound logic and data to argue that the idea of reasoning processes that operate independent of the actual world is illusory.

One can make a case for the second reason (i.e., CogAT as inadequate) because evidence exists that the CogAT could be a culture-bound measure of gifted intellect (Wasserman \& Wasserman, 2017). Mean group differences exist in quantitative and verbal batteries of the CogAT, but have also been found in the what is assumed to be a culture-neutral component, known as the nonverbal battery (Carman et al., 2018). This finding is not unique to ability tests, as there is also ample evidence of the CogAT's convergent validity with other known measures of Gf (Lakin \& Gambrell, 2014). Given this evidence, a reasoned argument can be made that present measures of gifted intellect fall short of a full operationalization of $\mathrm{G} f$.

The third reason (i.e., test utility) can be advanced because of the known impact of poor cognitive testing utility on underrepresented groups (Carman, Walther, \& Bartsch 2018; Peters \& Engerrand, 2016; Peters \& Gentry, 2012). For example, using scores as the sole determinant and applying improper norms during the gifted identification process have shown to serve as gatekeepers for underrepresented student groups (Carman et al., Peters \& Engerrand; Peters \& Gentry). Therefore, data exist supporting the argument that CogAT was used inappropriately, therefore possibly responsible for the disproportional enrollment across student race and SES.

The fourth reason (i.e., moderator) can be defended by the idea that a moderator unaccounted for in this study's design lead to the results encounter. For example, mental illness is known to covary with Gf (Keyes, Platt, Kaufman, \& McLaughlin, 2017). As such, active symptoms of attention deficit/hyperactivity disorder, conduct disorder, and/or oppositional defiance have been known to interfere with cognitive functioning and result in lower scores on assessments measuring $\mathrm{G} f$ (Keyes et al.). Mental health status in this study is not completely unaccounted because of the SES variable. SES has served in prior studies as a proxy for mental health status (McLaughlin, Costello, Leblanc, Sampson, \& Kessler, 2012). As such, data shows it is possible that actual differences in achievement exist across groups of students based on variables that were not directly analyzed such as mental illness.

Which of the four proceeding explanations of the obtained results concerning race/ethnicity and SES has the greatest explanatory likelihood? Use of Occam's Razor suggests the first (i.e., $\mathrm{G} f$ construct). $\mathrm{G} f$ is the most commonly used construct used to identify giftedness in U.S children (McBee, Peters, \& Miller, 2016). As such, the construct produces a foundational template and shapes all related gifted programming. Gifted programs in the US seek to identify students that show adaptive skills and achievement that are consistent with mainstream Western culture and values (Sternberg, 2018); creating a culture-bound construct. This results in the overidentification of students who are fluent in the sociocultural context embedded in Western educational systems, and the under-identification of those who aren't. While the second argument pertaining to the CogAT is surely a contributing factor because the assessment's purpose is to measure fluid intelligence (Lakin \& Gambrell, 2014), when 
looked at more critically, the CogAT is only a reflection of a culture-bound construct. For example, underrepresented student groups may possess gifts and talents specific to their own sociocultural context (Sternberg, 2018), but such skills being identified are beyond the measurement capacity of the CogAT. The utility of the CogAT could also be a factor, but the participating district did not elaborate beyond the usage of a multi-step identification process and the utilization of national norms. Therefore, we can assume then, that the utility of the CogAT's Standard Age Score (SAS) was used as only part of multiple pieces of data, rather than the sole determinant for student access. While national norms were utilized by the participating district is it difficult to know how the identification and norming process interacted with one another and contributed to the disproportional results. This rationale is supported by a similar argument in a study with one sample utilizing the CogAT as part of a multi-step identification process (Carman et al., 2018), as such there is a lack of sufficient evidence to make the claim that the utility of the CogAT could be responsible. The argument that the comorbidity between mental health disorders and fluid intelligence is relevant; however, a high prevalence of mental health disorders that would have caused the disproportionalities across groups would be rare specifically because the onset of most behavioral disorders begins around early adolescence (Merikangas et al., 2010) and the sample was comprised of first grade students. Additionally, SES has been used as a proxy for mental illness, but a lack of evidence exists to show the overall association low SES has on mental health (McLaughlin et al., 2012). Thus, showing that while the web of gifted disproportionality is complex and surely interrelated, the root cause of the present disproportionalities can most likely be determined by turning to a theory of intelligence bound by Western societal norms and values.

With respect to gender, there are two possible reasons for the results obtained. The first explanation addresses differences in academic performance across gender, differences evident in young children (Pomerantz, Altermatt, \& Saxon, 2002). Altermatt, \& Saxon, 2002). Specifically, regarding the CogAT, females have scored better on the verbal battery while males have excelled on the quantitative battery (Lohman \& Lakin, 2009). Second, the CogAT has shown trends in overidentifying males. The variability hypothesis holds true against the CogAT, where an overrepresentation of males occurs in tails of ability distribution (Johnson, Carothers, \& Deary, 2008; Lakin \& Gambrell, 2012; Lakin \& Gambrell, 2014, Petersen, 2013). Johnson et al. (2008) identified substantial sex differences on the extremes of ability distribution across the CogAT batteries. Lakin and Gambrell (2014) reported similar findings, where males showed higher variability across CogAT batteries. Of the two options, the explanation of the CogAT as overidentifying males is the most plausible; research has shown that the assessment consistently selects for males at the extremes of ability distribution. Gifted programs seek to identify those who are two standard deviations from the mean. Therefore, if males often score at the extreme ends of the tails, including two standard deviations both above and below, this would explain the overrepresentation of males in these results.

\section{Limitations}

The inferential nature of the one-sample $z$ test of proportions lends itself to making generalizations about the larger population. Given that gifted students comprise a small proportion of students is the general population, one must be careful when 
drawing conclusions from a small sample. Future research might, in this spirit, collect more samples to generate a larger $n$.

A second limitation would be the binomial nature of the race variable in this study. The original variable was multinomial with five categories (Alaskan Native/American Indian, Black, Hispanic, multi-racial, Pacific Islander). To address the issue of small category counts, race was collapsed into two categories:

"overrepresented" and "underrepresented." Future research should then attempt to collect a sufficiently large sample to effectively evaluate the relationship between specific racial groups and gifted program enrollment to better understand and advocate for marginalized groups.

\section{Implications}

This study has implications in the areas of the current gifted construct and its controlling definitions, evaluative tools, and future research prospects. First, starting with the foundation, considerations should address a construct that is increasingly unsustainable within a rapidly changing and diverse society. Gifted definitions and appendages of the gifted construct privilege fluid intelligence by association, even when inclusive language, acknowledging of multicultural needs, is included in operative definitional metrics. No longer is it appropriate to blame certain forms of identification tools for disproportionality rates; such tools are only measuring a highly culturally bounded construct. A shift in conceptualizing giftedness is necessary-a shift that reframes the construct itself, basing the revised approach on a skill set adaptive to specific social contexts.

Given the above described boundness, there are also certain implications for gifted measurement practices. Specifically, dynamic assessment is a more accurate approach for quantifying what a student from a non-mainstream culture should know or should have the ability to know (Sternberg, 2018). Dynamic testing examines performance over time, allowing students to develop familiarity toward a type of test (Sternberg). In other words, dynamic assessment enables the tester to show learning based on experience.

School counselors adhere to advocacy competencies in their practice and are often involved with the gifted nomination process. Bringing about awareness of the disproportionalities in their own site-based gifted programs or district level programs can begin much needed conversations in the restructuring of gifted policies and practices. While school counselors are not experts in the assessment of gifted children, they hold integral roles as advocates for equity and inclusion. In sum, the present study underscores the need for an approach that focuses on student racial predictor variables and cognitive-testing outcomes using the dynamic assessment approach.

\section{References}

Alvesson, M., \& Sandberg, J. (2011). Generating research questions through problematization. Academy of Management Review, 36, 247-271. http://dx.doi.org/10.5465/amr.2009.0188

Archambault, F. X., Westberg, K. L., Brown, S. W., Hallmark, B. W., Emmons, C. L., \& Zhang, W. (1993). Regular classroom practices with gifted students: Results of a national survey of classroom teachers. Storrs, CT: National 
Research Center on the Gifted and Talented.

Beisser, S. R. (2008). Unintended consequences of No Child Left Behind mandates on gifted students. Forum on Public Policy. Retrieved from http://forumonpublicpolicy.com/ summer08papers/archivesummer08/beisser.pdf

Bell, D. (1995). Who's afraid of critical race theory? University of Illinois Law Review, 1995, 893-910.

Berger, E. (2019). Multi-tiered approaches to Trauma-Informed Care in schools: A systematic review. School Mental Health, 1-15. https://doi.org/10.1007/s12310019-09326-0

Brown, C. L. (2004). Reducing the over-referral of culturally and linguistically diverse students (CLD) for language disabilities. NABE Journal of Research and Practice, 2, 225-243.

Callahan, C. M. (2005). Identifying gifted students from underrepresented populations. Theory Into Practice, 44, 98-104. http://dx.doi.org/10.1207/s15430421tip4402_4

Callahan, C. M., \& Hertberg-Davis, H. L. (2012). Fundamentals of gifted education: Considering multiple perspectives. New York, NY: Routledge.

Campbell, J. R., \& Walberg, H. J. (2010). Olympiad studies: Competitions provide alternatives to developing talents that serve national interests. Roeper Review, 33, 8-17. http://dx.doi.org/10.1080/02783193.2011.530202

Card, D., \& Giuliano, L. (2016). Universal screening increases the representation of low-income and minority students in gifted education. Proceedings of the National Academy of Sciences, 113, 13678-13683. https://doi.org/10.1073/pnas.1605043113

Carman, C. A., Walther, C. A., \& Bartsch, R. A. (2018). Using the Cognitive Abilities Test (CogAT) 7 nonverbal battery to identify the gifted/talented: An investigation of demographic effects and norming plans. Gifted Child Quarterly, 62, 193-209. https://doi.org/10.1177/0016986217752097

Cattell, R. B. (1963). Theory of fluid and crystallized intelligence: A critical experiment. Journal of educational psychology, 54, 1-22. http://dx.doi.org/10.1037/h0046743

Daftary, Ashley-Marie Hanna. (2018). Critical race theory: An effective framework for social work research. Journal of Ethnic \& Cultural Diversity in Social Work. https://doi.org/10.1080/15313204.2018.1534223

Daly, L., \& Bourke, G. J. (2008). Interpretation and uses of medical statistics. New York, NY: John Wiley \& Sons.

Elhoweris, H., Mutua, K., Alsheikh, N., \& Holloway, P. (2005). Effect of children's ethnicity on teachers' referral and recommendation decisions in gifted and talented programs. Remedial and Special Education, 26, 25-31. https://doi.org/10.1177/07419325050260010401

Every Student Succeeds Act, Pub. L. No. 114-95 (2015).

Farkas, S., \& Duffett, A. (2008). Results from a national teacher survey. High achieving students in the era of NCLB (pp. 49-71). Washington, DC: Thomas B. Fordham Institute.

Faul, F., Erdfelder, E., Buchner, A., \& Lang, A.-G. (2009). Statistical power analyses using $G^{*}$ Power 3.1: Tests for correlation and regression analyses. Behavior 
Research Methods, 41, 1149-1160. doi:10.3758/BRM.41.4.1149

Ford, D. Y. (1998). The underrepresentation of minority students in gifted education: Problems and promises in recruitment and retention. The Journal of Special Education, 32, 4-14. https://doi.org/10.1177/002246699803200102

Ford, D. Y. (2010). Underrepresentation of culturally different students in gifted education: Reflections about current problems and recommendations for the future. Gifted Child Today, 33, 31-35. https://doi.org/10.1177/107621751003300308

Ford, D. Y., Grantham, T. C., \& Whiting, G. W. (2008). Culturally and linguistically diverse students in gifted education: Recruitment and retention issues. Exceptional Children, 74, 289-306.

Goings, R. B., \& Ford, D. Y. (2018). Investigating the intersection of poverty and race in gifted education journals: A 15-year analysis. Gifted Child Quarterly, 62, 25-36. doi:10.1177/0016986217737618

Grantham, T. C. (2002). Underrepresentation in gifted education: How did we get here and what needs to change? Roeper Review, 24, 50-52.

Grissom, J. A., \& Redding, C. (2015). Discretion and disproportionality: Explaining the underrepresentation of high-achieving students of color in gifted programs. AERA Online, 2, 1-15. https://doi.org/10.1177/2332858415622175

Hamilton, R., McCoach, D. B., Tutwiler, M. S., Siegle, D., Gubbins, E. J., Callahan, C. M., ...Mun, R. U. (2018). Disentangling the roles of institutional and individual poverty in the identification of gifted students. Gifted Child Quarterly, 62, 6-24. doi:10.1177/0016986217738053

Harris, A. J., Rowley, M. G., Beck, S. R., Robinson, E. J., \& McColgan, K. L. (2011). Agency affects adults', but not children's, guessing preferences in a game of chance. The Quarterly Journal of Experimental Psychology, 64, 1772-1787. http://dx.doi.org/10.1080/17470218.2011.582126

Harwell, M., \& LeBeau, B. (2010). Student eligibility for a free lunch as an SES measure in education research. Educational Researcher, 39, 120-131. https://doi.org/10.3102/0013189X10362578

Johnson, W., Carothers, A., \& Deary, I. J. (2008). Sex differences in variability in general intelligence: A new look at the old question. Perspectives on Psychological Science, 3, 518-531. https://doi.org/10.1111/j.17456924.2008.00096.x

Keyes, K. M., Platt, J., Kaufman, A. S., \& McLaughlin, K. A. (2017). Association of fluid intelligence and psychiatric disorders in a population-representative sample of US adolescents. JAMA psychiatry, 74, 179-188. doi:10.1001/jamapsychiatry.2016.3723

Kids Count Data Center. (2016). Child population by gender. Baltimore, MD: Annie E. Casey Foundation. Retrieved from: http://datacenter.kidscount.org/data/tables/102-childpopulation-bygender?loc=30\&loct=2\#detailed/2/30/false/573,869,36,868,867/14,15,65/421, 422

Lakin, J. M., \& Gambrell, J. L. (2012). Distinguishing verbal, quantitative, and figural facets of fluid intelligence in young students. Intelligence, 40, 560-570. 
https://doi.org/10.1016/j.intell.2012.07.005

Lakin, J. M., \& Gambrell, J. L. (2014). Sex differences in fluid reasoning: manifest and latent estimates from the cognitive abilities test. Journal of Intelligence, 2, 36-55. https://doi.org/10.3390/jintelligence2020036

Lohman, D. F., \& Lakin, J. M. (2009). Consistencies in sex differences on the Cognitive Abilities Test across countries, grades, test forms, and cohorts. British Journal of Educational Psychology, 79, 389-407. https://doi.org/10.1348/000709908X354609

Mann, C. J. (2003). Observational research methods. Research design II: cohort, cross sectional, and case-control studies. Emergency Medicine Journal, 20, 54-60. doi:10.1136/emj.20.1.54

Marquardt, R. G., \& Karnes, F. A. (1995). Gifted education and discrimination: The role of the Office for Civil Rights. Talents and Gifts, 18, 87-94. https://doi.org/10.1177/016235329401800107

McBee, M. T. (2006). A descriptive analysis of referral sources for gifted identification screening by race and socioeconomic status. Journal of Secondary Gifted Education, 17, 103-111. https://doi.org/10.4219/jsge-2006686

McBee, M. T., Peters, S. J., \& Miller, E. M. (2016). The impact of the nomination stage on gifted program identification: A comprehensive psychometric analysis. Gifted Child Quarterly, 60, 258-278. https://doi.org/10.1177/0016986216656256

McLaughlin, K. A., Costello, E. J., Leblanc, W., Sampson, N. A., \& Kessler, R. C. (2012). Socioeconomic status and adolescent mental disorders. American Journal of Public Health, 102, 1742-1750. doi:10.2105/AJPH.2011.300477

Naglieri, J. A., \& Ford, D. Y. (2003). Addressing underrepresentation of gifted minority children using the Naglieri Nonverbal Ability Test (NNAT). Gifted Child Quarterly, 47, 155-160. https://doi.org/10.1177/001698620304700206

National Association for Gifted Children. (2015). State of the states in gifted education: Policy and practice data 2014-2015. Washington, DC: Author. Retrieved from http://www.nagc.org/sites/default/files/key\%20reports/2014 $2015 \% 20$ State $\% 20$ of\%20the \%20States\%20summary.pdf

National Association for Gifted Children. (2017). Retrieved from http://nagc.org

No Child Left Behind Act of 2001, P.L. 107-110, 20 U.S.C. § 6319 (2002).

Office for Civil Rights. (2014). Civil rights data collection. Gifted and talented, 2013-2014 [Data file]. Retrieved from https://ocrdata.ed.gov/StateNationalEstimations/Estimations_2013_14

Office for Civil Rights. (2018). Retrieved from https://www2.ed.gov/about/offices/list/ocr/index.html

Olszewski-Kubilius, P., \& Corwith, S. (2018). Poverty, academic achievement, and giftedness: A literature review. Gifted Child Quarterly, 62, 37-55. https://doi.org/10.1177/0016986217738015

Pepperell, J. L., \& Rubel, D. J. (2009). The experience of gifted girls transitioning from elementary school to sixth and seventh grade: A grounded theory (Doctoral dissertation). The Qualitative Report, 14, 341-360. 
http://ir.library.oregonstate.edu/concern/graduate_thesis_or_dissertations/445 $58 \mathrm{~g} 82 \mathrm{C}$

Peters, S. J., \& Engerrand, K. G. (2016). Equity and excellence: Proactive efforts in the identification of underrepresented students for gifted and talented services. Gifted Child Quarterly, 60, 159-171. https://doi.org/10.1177/0016986216643165

Peters, S. J., \& Gentry, M. (2012). Group-specific norms and teacher-rating scales: Implications for underrepresentation. Journal of Advanced Academics, 23, 125-144. https://doi.org/10.1177/1932202X12438717

Petersen, J. (2013). Gender differences in identification of gifted youth and in gifted program participation: A meta-analysis. Contemporary Educational Psychology, 38, 342-348. https://doi.org/10.1016/j.cedpsych.2013.07.002

Pfeiffer, S. I., \& Jarosewich, T. (2007). The Gifted Rating Scales-School Form: An analysis of the standardization sample based on age, gender, race, and diagnostic efficiency. Gifted Child Quarterly, 51, 39-50. https://doi.org/10.1177/0016986206296658

Pomerantz, E. M., Altermatt, E. R., \& Saxon, J. L. (2002). Making the grade but feeling distressed: Gender differences in academic performance and internal distress. Journal of Educational Psychology, 94, 396. http://doi:10.1037/00220663.94.2.396

Reis, S. M., \& McCoach, D. B. (2000). The underachievement of gifted students: What do we know and where do we go? Gifted Child Quarterly, 44, 152-170. https://doi.org/10.1177/001698620004400302

Reis, S. M., \& Renzulli, J. S. (2010). Is there still a need for gifted education? An examination of current research. Learning and Individual Differences, 20, 308-317. https://doi.org/10.1016/j.lindif.2009.10.012

Renzulli, J. S. (1978). What makes giftedness? Reexamining a definition. Phi Delta Kappan, 60, 180. https://doi.org/10.1177/003172171109200821

Rosnow, R. L., \& Rosenthal, R. (2003). Effect sizes for experimenting psychologists. Canadian Journal of Experimental Psychology/Revue Canadienne de Psychologie Expérimentale, 57, 221-237. http://dx.doi.org/10.1037/h0087427

Sadker, D. (2000). Gender equity: Still knocking at the classroom door. Equity \& Excellence in Education, 33, 80-83. https://doi.org/10.1080/1066568000330112

Slocomb, P. D., \& Payne, R. K. (2000). Removing the mask: Giftedness in poverty. RFT Pub.

Stephens, K. R., \& Karnes, F. A. (2000). State definitions for the gifted and talented revisited. Exceptional Children, 66, 219-238. https://doi.org/10.1177/001440290006600206

Sternberg, R. J. (2018). Context-sensitive cognitive and educational testing. Educational Psychology Review, 30, 857-884. https://doi.org/10.1007/s10648017-9428-0

Swanson, J. D. (2006). Breaking through assumptions about low-income, minority gifted students. Gifted Child Quarterly, 50, 11-25.

https://doi.org/10.1177/001698620605000103

Tadajewski, M., \& Hewer, P. (2011). Intellectual contributions and gap-spotting. 
Journal of Marketing Management, 27, 449-457. http://dx.doi.org/10.1080/0267257X.2011.562364

Wasserman, T., \& Wasserman, L. D. (2017). Touching the elephant: The search for fluid intelligence. Applied Neuropsychology: Child, 6, 228-236. https://doi.org/10.1080/21622965.2017.1317489

Wright, B. L., Ford, D. Y., \& Young, J. L. (2017). Ignorance or indifference? Seeking excellence and equity for under-represented students of color in gifted education. Global Education Review, 4, 45-60.

Yaluma, A., \& Tyner, C. B. (2018). Is there a gifted gap? Gifted education in highpoverty schools. Retrieved from https://edexcellence.net/publications/is-therea-gifted-gap

Yoon, S. Y., \& Gentry, M. (2009). Racial and ethnic representation in gifted programs: Current status of and implications for gifted Asian American students. Gifted Child Quarterly, 53, 121-136.

doi:10.1177/0016986208330564 